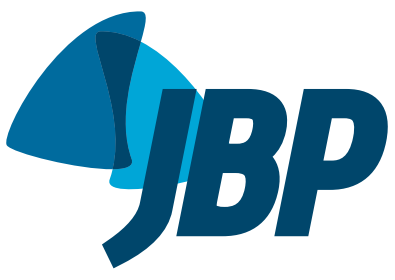

\title{
Pulmonary rehabilitation in severe COPD with hyperinflation: some insights into exercise performance
}

\author{
Luiz Alberto Forgiarini Junior ${ }^{1}$, Antonio Matias Esquinas ${ }^{2}$
}

We would like to highlight the importance of the study entitled "Exercise performance and differences in physiological response to pulmonary rehabilitation in severe chronic obstructive pulmonary disease with hyperinflation",(1) which was recently published in the JBP. The authors evaluated the impact of pulmonary rehabilitation on exercise tolerance in severe COPD with hyperinflation. That study showed improvement in oxygen consumption, reduced carbon dioxide production, and decreased respiratory drive; however, patients with post-exercise hyperinflation did not improve their maximal performance. We congratulate the authors for the important findings, but some key issues need to be taken into account for a proper clinical extrapolation.

First, it is unclear whether those patients with hyperinflation after exercise had peripheral muscle weakness prior to pulmonary rehabilitation or not. Second, we wonder if hyperinflation was significantly higher in those patients when they were compared with those who responded to pulmonary rehabilitation. In this line, a possible evaluation tool would be the handgrip, as demonstrated by Burtin et al., (2) who evaluated patients with COPD and showed what could be a tool associated with a prognosis of mortality in this population. Third, the authors evaluated the chest wall with the utilization of optoelectronic plethysmography; however, the respiratory muscles were not evaluated directly, which would be an interesting factor given the fact that there are studies demonstrating that the sensation of dyspnea might be associated with respiratory muscle weakness, and the training of these muscles, in association with pulmonary rehabilitation, results in a reduction in dyspnea indices. ${ }^{(3)}$ We consider that other alternatives for COPD patients with chronic hyperinflation after exercise and submitted to a pulmonary rehabilitation program should be evaluated in this population. As an example, Monteiro et al. ${ }^{(4)}$ showed that the use of expiratory positive airway pressure in patients with moderate and severe COPD can reduce dynamic hyperinflation after a submaximal exercise. Similarly, Wibmer et al. ${ }^{(5)}$ evaluated the lung volumes in COPD patients undergoing exercise with the use of positive expiratory pressure via a nasal mask; the authors demonstrated a significant reduction in dynamic hyperinflation during a walking exercise.

We must highlight the importance of the study by Albuquerque et al., ${ }^{(1)}$ since COPD patients with post-exercise hyperinflation are a reality in outpatient rehabilitation, and adequate knowledge of the response to treatment is of great importance so that new studies with a focus on actions that can alleviate this condition can be carried out. In addition, further prospective clinical trials need to confirm such data.

\section{REFERENCES}

1. Albuquerque AL, Quaranta M, Chakrabarti B, Aliverti A, Calverley PM. Exercise performance and differences in physiological response to pulmonary rehabilitation in severe chronic obstructive pulmonary disease with hyperinflation. J Bras Pneumol. 2016;42(2):121-9. http:// dx.doi.org/10.1590/S1806-37562015000000078

2. Burtin C, Ter Riet G, Puhan MA, Waschki B, Garcia-Aymerich J, Pinto-Plata $V$, et al. Handgrip weakness and mortality risk in COPD: a multicentre analysis. Thorax. 2016;71(1):86-7. http://dx.doi.org/10.1136/ thoraxjnl-2015-207451

3. Beaumont M, Mialon P, Le Ber-Moy C, Lochon C, Péran L, Pichon R, et al. Inspiratory muscle training during pulmonary rehabilitation in chronic obstructive pulmonary disease: A randomized trial. Chron Respir Dis. 2015;12(4):305-12. http://dx.doi.org/10.1177/1479972315594625

4. Monteiro MB, Berton DC, Moreira MA, Menna-Barreto SS, Teixeira PJ. Effects of expiratory positive airway pressure on dynamic hyperinflation during exercise in patients with COPD. Respir Care. 2012;57(9):140512. http://dx.doi.org/10.4187/respcare.01481

5. Wibmer T, Rüdiger S, Heitner C, Kropf-Sanchen C, Blanta I, Stoiber $\mathrm{KM}$, et al. Effects of nasal positive expiratory pressure on dynamic hyperinflation and 6-minute walk test in patients with COPD. Respir Care. 2014;59(5):699-708. http://dx.doi.org/10.4187/respcare.02668

\footnotetext{
1. Programa de Pós-Graduação em Reabilitação e Inclusão e Programa de Pós-Graduação em Biociências e Reabilitação, Curso de Fisioterapia, 


\section{AUTHORS' REPLY}

Andre Luis Pereira de Albuquerque ${ }^{1,2}$, Marco Quaranta ${ }^{3}$, Biswajit Chakrabarti ${ }^{4}$, Andrea Aliverti ${ }^{3}$, Peter M. Calverley ${ }^{4}$

We would like to thank Forgiarini Junior and Esquinas for their comments, precisely because they address highly relevant issues related to the chances of success of pulmonary rehabilitation in severe COPD. Our colleagues properly pointed out that patients with more advanced COPD may also have peripheral muscle weakness, which can be a limiting factor for maximal performance gain through cardiopulmonary rehabilitation. In our study, the COPD patients who showed no improvement following rehabilitation had higher leg fatigue values before the intervention than did those who showed improvement. In addition, the degree of fatigue was not reduced after training in the patients who did not respond to rehabilitation. It is in fact to be assumed that peripheral skeletal muscle involvement in those patients is not restricted to the legs but is also present in the arms. ${ }^{(1)}$ For this reason, handgrip evaluation can identify patients with a potentially poorer response in terms of exercise capacity after cardiopulmonary rehabilitation.
In addition to the impact of various organs as limiting factors in COPD, no static or dynamic assessment of the respiratory muscles was performed in our study. Ventilatory weakness can certainly be an additional factor contributing to a greater sensation of dyspnea, as our colleagues pointed out. However, in such patients, one of the major problems is mechanical inefficiency secondary to dynamic air trapping during exercise. Because of this inefficiency, even with strength being generated by the ventilatory muscles, there is no proportional increase in ventilatory flow. As a result, fatigue occurs mainly in the inspiratory muscles in this state of inefficiency and high ventilatory demand.(2) Undoubtedly, complementary therapies that reduce air trapping and result in increased exercise tolerance during rehabilitation, such as the use of noninvasive ventilation, mentioned by our colleagues, should be considered for such groups of patients with severe COPD, especially for those with pulmonary hyperinflation.

We do agree that future studies addressing these multiple limiting factors in COPD are extremely important $^{(3)}$ so that our patients can achieve a decrease in their sensation of dyspnea and an improvement of endurance in their activities of daily living.

\section{REFERENCES}

1. Maltais F, Decramer M, Casaburi R, Barreiro E, Burelle $Y$, Debigaré $\mathrm{R}$, et al. An official American Thoracic Society/European Respiratory Society statement: update on limb muscle dysfunction in chronic obstructive pulmonary disease. Am J Respir Crit Care Med. 2014;189(9): e15-62. http://dx.doi.org/10.1164/rccm.201402-0373ST

2. O'Donnell DE, Hamilton AL, Webb KA. Sensory-mechanical relationships during high-intensity, constant-work-rate exercise in COPD. J Appl Physiol (1985). 2006;101(4):1025-35. http://dx.doi. org/10.1152/japplphysiol.01470.2005

3. O'Donnell DE, Laveneziana P, Webb K, Neder JA. Chronic obstructive pulmonary disease: clinical integrative physiology. Clin Chest Med. 2014;35(1):51-69. http://dx.doi.org/10.1016/j.ccm.2013.09.008

\footnotetext{
1. Disciplina de Pneumologia, Instituto do Coração, Hospital das Clínicas, Faculdade de Medicina, Universidade de São Paulo, São Paulo (SP) Brasil.

2. Núcleo Avançado de Tórax, Laboratório de Função Pulmonar, Hospital Sírio-Libanês, São Paulo (SP) Brasil.

3. TBM Lab, Dipartimento di Elettronica, Informazione e Bioingegneria, Politecnico di Milano, Milano, Italia.

4. Clinical Sciences Centre, Aintree University Hospital, Liverpool, United Kingdom.
} 